\title{
AOR
}

Selected Papers of \#AolR2018:

The $19^{\text {th }}$ Annual Conference of the

Association of Internet Researchers

Montréal, Canada / 10-13 October 2018

\section{EXAMINING THE ROLE AND SIGNIFICANCE OF EMERGING SOCIAL NEWS OUTLETS AND THEIR ADVOCACY JOURNALISM IN THE 2017 AUSTRALIAN SAME-SEX MARRIAGE POSTAL SURVEY}

\author{
Edward Hurcombe \\ Digital Media Research Centre, Queensland University of Technology

\section{Introduction}

This paper examines emerging news forms and journalistic practices within Australia that are native to social media. It argues that these shared forms and practices constitute a new genre of 'social news'. Three Australian-based outlets are studied through the conceptual lens of social news - BuzzFeedOz News, Junkee Media, and Pedestrian.tv. Using digital tools alongside manual methods, this paper investigates the role and significance of these outlets on Twitter and Facebook during the same-sex marriage postal survey from August-November 2017. The survey was commissioned by the incumbent conservative Liberal-National Australian government to gauge nationwide support for same-sex marriage. Notably, these social news outlets played an advocacy role, breaking with journalistic norms around 'objectivity' and 'balance'.

\section{Background}

News material is increasingly accessed through social media, as Twitter and Facebook emerge as platforms for news engagement, sharing and discussion (Nielsen \& Schroder 2014). In turn, news-reading publics are co-evolving with these platforms, as the former become embedded within everyday sociable practices on platforms (Highfield 2016). Concurrently, news and journalism are transforming (Harrington 2012) alongside these emerging platform publics.

Social news embodies specific kinds of platform vernaculars (Gibbs et al 2014) and pop-cultural sensibilities. These vernaculars and sensibilities - which include acronyms, irony and humour, along with pop-cultural visual media like GIFs and memes - reflect a

Suggested Citation (APA): Hurcombe, E. (2018, October 10-13 Examining The Role And Significance Of Emerging Social News Outlets And Their Advocacy Journalism In The 2017 Australian Same-Sex Marriage Postal Survey. Paper presented at AolR 2018: The $19^{\text {th }}$ Annual Conference of the Association of Internet Researchers. Montréal, Canada: AolR. Retrieved from http://spir.aoir.org. 
deep connection to the cultures of social media platforms. The use of these vernaculars indicates social news' suitability for the kinds of everyday socialising prevalent on platforms, and social news' desire for shareability. In addition, such vernaculars particularly the use of GIFs, which act as affective gestures (Papacharissi 2015) within articles - demonstrate not only a blurring of 'serious' and 'entertaining' news content, but also an innovative use of explicit affect in engaging news-reading publics.

The editorial perspectives of social news outlets are frequently overt, a quality I term 'positionality'. This positioned perspective is distinct from an editorial bias concealed within seemingly 'objective' news content (Eveland \& Shah 2003). Social news outlets also eschew and critique 'balance', an established journalistic norm. 'Balance' aims to present both sides of any newsworthy issue. However, not all sides deserve equal attention, and as Boykoff \& Boykoff found in their work on climate science coverage in the US (2004), the requirement for 'balance' has in previously led otherwise respected outlets to mislead audiences by over-representing fringe perspectives.

Social news outlets' eschewing of balance was notable during the 2017 same-sex marriage postal survey, itself an exercise in 'hearing both sides' so as to stall policymaking on a well-supported human rights issue. Legacy news outlets like News Corp's The Daily Telegraph and Fairfax Media's The Sydney Morning Herald regularly ran provocative op-eds from 'No' advocates, the justification being that this was 'balance'. The national public broadcaster, the Australian Broadcasting Corporation, also was committed to neutrality. Conversely, social news outlets refrained from publishing 'No' op-eds. All three outlets encouraged enrolment, and Junkee Media and Pedestrian.tv actively advocated for the 'Yes' side. This advocacy journalism even steered into activism - as in mobilising action (Fisher 2016) - with the two outlets creating a '\#EnrolAndUpdate' hashtag on Twitter, encouraging their audiences to enrol and vote 'Yes'.

\section{Methods}

Both manual and automated digital methods were used to investigate the role and significance of social news reporting, advocacy and activism during the postal survey. For Twitter data, the tracking tool DMI-TCAT (Borra \& Rieder 2014) was used to track postal survey-related keywords. 'Postal survey', 'postal plebiscite', '\#EnrolAndUpdate', '\#EnrolForEquality' and '\#marriageequality' were tracked from 11 August 2017 - 17 November 2017, covering the period shortly after the survey was announced until two days after the results were announced. Within this dataset, social news actors - official accounts and the accounts of social news writers - were identified, and assessed in terms of visibility (based on retweets and @mentions). I currently lack access to detailed enrollment and voting data; however measuring visibility provides preliminary indications of impact. I am also currently working on methods to capture the most shared URLs, and domains, within this Twitter dataset. Manual tracking methods - such as screenshots, and hyperlink archiving - were also used to collect data outside of keyword parameters. On Facebook, these same manual methods were used to collect data on social news advocacy and activism.

\section{Preliminary findings}


Overall, social news actors were moderately-to-highly visible on Twitter during the postal survey period, in particular BuzzFeedOz News reporters Alice Workman (@workmanalice) and Lane Sainty (@lanesainty). During the 11 August - 17 November period, Workman and Sainty were the $15^{\text {th }}$ and $17^{\text {th }}$ most visible users, respectively. During 11 August - 28 August, before and immediately after the enrollment deadline, Workman and Sainty were the $4^{\text {th }}$ and $5^{\text {th }}$ most visible users. Also during this period, Osman Faruqi from Junkee Media was the $16^{\text {th }}$ most visible user. \#EnrolAndUpdate was also the $10^{\text {th }}$ most visible hashtag during 11-28 August; attracting 598 tweets. The official accounts of social news outlets had low visibility during both periods. All social news outlets were prolific during 11 August - 15 November, with Pedestrian.tv writing 183 articles about the survey, BuzzFeedOz News writing 182, and Junkee Media writing 146. Sainty was praised by activists and other journalists for her reporting. Junkee Media also received praise for their advocacy role by major 'Yes' activists. Facebookspecific activist efforts by Junkee Media encouraging users to enrol and vote 'Yes' included 1 video, 1 meme, and 4 articles, all posted before the deadline. Pedestrian.tv changed its Facebook profile and cover images to a 'Yes' logo, and posted an article encouraging users to enrol. BuzzFeedOz News also posted 3 articles to Facebook encouraging enrolment. These posts had varying levels of engagement, although the Junkee video received over 3,300 views. All of these videos and articles used platform vernaculars, including pop-cultural imagery.

These preliminary findings allow some conclusions to be drawn. Firstly, the prominence of some social news actors on Twitter during the survey indicates a shifting - although not totally transformed - Australian news ecology. Secondly, social news outlets' lack of 'balance' indicates a growing challenge from emerging outlets to traditional journalistic norms within Australia. Significantly, in this case the challenge comes not from hyperpartisan outlets trading in propaganda and disinformation (Marwick \& Lewis, 2017), but from outlets that intelligently critique the value in giving a platform to 'both sides'. Thirdly, these findings demonstrate how new forms of advocacy and activist journalism are utilising, to mixed success, pop-culture-infused platform vernaculars to engage news-reading publics on social media. Overall, this research is useful in highlighting that disruptions from social media platforms and cultures can be sources of positive potential for news and journalistic practice.

\section{References}

Borra, E. and Rieder, B. (2014) 'Programmed method: Developing a toolset for capturing and analyzing tweets', Aslib Journal of Information Management, 66(3), pp. 262-278.

Boykoff, M. T. and Boykoff, J. M. (2004) 'Balance as bias: Global warming and the US prestige press', Global Environmental Change, 14(2), pp. 125-136.

Eveland Jr, W. P. and Shah, D. V. (2003) 'The impact of individual and interpersonal factors on perceived news media bias', Political Psychology, 24(1), pp. 101-117.

Fisher, C. (2016) 'The advocacy continuum: Towards a theory of advocacy in journalism', Journalism, 17(6), pp. 711-726. 
Gibbs, M., Meese, J., Arnold, M., Nansen, B. and Carter, M. (2015) '\#Funeral and Instagram: Death, social media, and platform vernacular', Information, Communication \& Society, 18(3), pp. 255-268.

Harrington, S. (2012) 'Australian journalism studies after "journalism": Breaking down the disciplinary boundaries (for good)', Media International Australia, (144), pp. 156162.

Highfield, T. (2016) Social Media and Everyday Politics. Cambridge: Polity.

Marwick, A. and Lewis, R. (2017) Media Manipulation and Disinformation Online, Data \& Society Research Institute.

Nielsen, R. K. and Schrøder, K. C. (2014) 'The relative importance of social media for accessing, finding, and engaging with news', Digital Journalism. Routledge, 2(4), pp. 472-489.

Papacharissi, Z. (2015) Affective Publics: Sentiment, Technology and Politics. Oxford: Oxford University Press. 